\title{
Surface-Functionalized Polymer Fibers for Highly Efficient Removal of Metal Ions from Aqueous Solution
}

\author{
Mithon Majumder ${ }^{1}$, Jingzhao Zheng1, Yuhang Liu ${ }^{1}$, Wei Wei ${ }^{1,2}$, Yi Zhou ${ }^{1,2}$, Yang Zhou ${ }^{1,2 *}$ and Zhongmin \\ Deng ${ }^{1,2 *}$ \\ ${ }^{1}$ School of Textile Science and Engineering, Wuhan Textile University, China
}

${ }^{2}$ State Key Laboratory of New Textile Materials and Advanced Processing Technology, Wuhan Textile University, China

*Corresponding author: Yang Zhou, School of Textile Science and Engineering, Wuhan Textile University, China.
Received Date: August 14, 2020

Published Date: August 28, 2020

\begin{abstract}
Lots of various techniques are applied to remove heavy metal ions from the environment. Adsorption method is well known as a very simple and economic technique. Herein, we reviewed the effective functionalization and modification of polyacrylonitrile fibers which be used as adsorbents for efficient adsorption and selective removal of metal ions from aqueous solution. Polyacrylonitrile fibers are known as good adsorbents due to its large surface and fluffy structure as well as excellent weatherability and stability for general chemicals. The cyano group in polyacrylonitrile molecule can be easily modified with various designed fuctionalized chemicals with special chelating groups according to application field. In this review, we summarized the general modification methods, adsorption techniques, effect of $\mathrm{pH}$, initial concentration of ions, effect of contact time and desorption or recovery of polyacrylonitrile fibers. A large kind of metal ions including $\mathrm{Cu}(\mathrm{II}), \mathrm{Ni}(\mathrm{II}), \mathrm{Pb}(\mathrm{II}), \mathrm{Hg}(\mathrm{II}), \mathrm{Fe}(\mathrm{III}), \mathrm{Ag}(\mathrm{I}), \mathrm{Zn}$ (II), $\mathrm{Cr}(\mathrm{III})$, $\mathrm{Cr}(\mathrm{VI}), \mathrm{Cd}(\mathrm{II}), \mathrm{Pt}(\mathrm{II})$ and $\mathrm{Pd}(\mathrm{II})$ are all recorded.
\end{abstract}

\section{Introduction}

Nowadays pollution becomes a major concern for living environment. The heavy metal ions which lead to heavyity, contamination of water is a great contributor to environmental pollution. There are several accidents occurred by heavy metal ions which becomes a great concern about river safety [1-3]. In general, heavy metalions are generated from the industry including battery manufacturer, metal plating, fossil fuels, fertilizer plants, tannery, mining plants, etc. These heavy metal ions are seriously harmful to human beings as well as wildlife which can cause death problems [4].

Versatile techniques including ion-exchange, solvent extraction, chemical precipitation, coagulation- flocculation, flotation, membrane separation, electrochemical treatment, reverse osmosis and adsorption have been utilized to fulfill the task [5]. Among these ways, adsorption is common well known as attractive way due to its removal efficiency as well as excellent reusability [6]. Activated carbon, oxide minerals, polymer materials, resins and bio sorbents have been applied as absorbents to extract metal ions from the aqueous solution. The efficiency of the absorption depends on the capability of the absorbents, where immobilized functional groups play a dominant role in it.

The performance of the adsorbents exceedingly depends on their physical and chemical properties. It is remarkable that adsorption is a surface phenomenon [7]. The adsorption efficiency depends on the adsorbent capability to concentrate or absorb metal ions from the solution which is separated or removed from the aqueous solution onto its surface. There are several types of adsorbents including activated carbon, oxide minerals, polymer fibers, resins, and bio sorbents [8] that have been used to adsorb 
metal ions or to enrich trace amounts of metal ions from various aqueous solutions. There are several fibers are treated as an absorbent to remove heavy metal from contaminated water for their large surface area. The surface functional groups of the adsorbent would be controlled for the adsorption of metal ions from the polluted water [9]. polyacrylonitrile (PAN) fibers are well known as highly efficient materials for the removal of heavy metal ions from solutions with high adsorption capacity and fast adsorption equilibrium due to large surface area, chemical resistance, thermal stability, low flammability as well as good mechanical properties.

There are many modifications of polyacrylonitrile (PAN) for the adsorbent of heavy metal ions. Due to the presence of nitrile groups on PAN surfaces, several surface chemical modifications have been done to generate chelating functional groups on its surface. These chelating functional groups include amidoxime, imidazole, Ethylenediamine, Diethylenetriamine, Iminodiacetic acid,

Hydroxylamine Hydrochloride, chitosan, Nitric acid, Thiourea, Hydrolyzed, Thioamidated, Hydroxylamine, (3-mercaptopropyl) tri-methoxysilane, Acrylamide, ethylenediamine, ethylene glycol, metal oxides, carboxyl or phosphoryl derivatives and pedant amine groups. These functional groups came about as results of chemical reactions such as amination, amidoximation and hydrolysis. Amination involves the grafting of amine-containing ligands on the surfaces of PAN fibers [2,10-13].

Nowadays, nano filaments are extremely mainstream to use as an adsorbent for their high surface area as indicated by mass proportion. Nanobeads, nanocomposites, nano-adsorbents, nanofiber attractive nano adsorbents have been broadly created. Nanofiber have drawn a lot of sights because of their recognized property focal points, for example, high porosity, the substantial surface zone per unit mass, and high gas penetrability, which causes demonstrated higher adsorption limit. For instance, the adsorption of chitosan adjusted electro spun nanofiber for $\mathrm{Cu}$ (II) particles were 6 and 11 times more noteworthy than the height estimations of microsphere chitosan and the plain chitosan.

PAN fibers are known as acrylic fibers, which has strong mechanical strength, excellent weather ability, and antibiotic property, chemical stability, and thermostability. So, it has been applied broadly in the manufacture of the textile products and in the industrial development of sunshade, thermal insulation material, filtration materials, etc. In addition, PAN fibers often act as a raw material for the preparation of various functional materials. Through the translation of cyano- into other function groups, various kinds of functional materials have been prepared from PAN fibers. For examples, the reaction of PAN fibers with phenylhydrazine or para-toluene sulfamide has been used to synthesize chelating ion exchange fiber containing $\mathrm{N}, \mathrm{N}$ and $\mathrm{N}, \mathrm{O}$ ligands for the enrichment of $\mathrm{Au}(\mathrm{III}), \mathrm{Pt}(\mathrm{IV}), \mathrm{Pd}(\mathrm{IV}), \mathrm{Ru}(\mathrm{III}), \mathrm{Rh}(\mathrm{III})$, $\mathrm{V}(\mathrm{V})$, Ti (IV), Ga(III), In(III), and Bi(III) etc.

Another two chelating ion exchange fibers, which contained $\mathrm{S}$ and $\mathrm{P}$ polydentate ligand, were prepared by modifying polyacrylonitrile initially with hydrazine hydrate, then with diethylenetriamine, followed by treatment with sodium sulfide and metaphosphoric acid. These two fibers possess high selectivity and efficiency to the adsorption of $\mathrm{Cu}(\mathrm{II}), \mathrm{Zn}(\mathrm{II}), \mathrm{Cd}(\mathrm{II})$, and $\mathrm{Hg}$ (II) [4-5]. So, the highly efficient adsorbent is always required in the removal and enrichment of metal ions from polluted water, it is of value for exploiting new, versatile function materials through chemical modification of PAN fibers [14].

\section{Surface Modified PAN Fibers}

Among different mechanism chelation and ion exchange have been treated as a great mechanism for adsorption of different heavy metal ions [13]. Among different mechanism chelation and ion exchange have been treated as a great mechanism for adsorption of different heavy metal ions [15]. It has been indicated that this surface existence of carboxyl, sulfonic and phosphonic groups which are favor to metal ion adsorption by the ion exchange mechanism, while metal ion adsorption continues through the chelation mechanism with the presence of nitrogen groups (amino, hydrazine, thioamide, and imidazoline). By diffusion or convection, metalions are transported to the adsorbent's surfaces from metal ion solution and the metal ions are attached to the floating functional group of the surface of the absorbent [16-18] (Figures $1 \& 2)$.

There are many heavy metals ions such as $(\mathrm{Cu}(\mathrm{II}), \mathrm{Ni}(\mathrm{II})$, $\mathrm{Pb}(\mathrm{II}), \mathrm{Hg}(\mathrm{II}), \mathrm{Fe}(\mathrm{III}), \mathrm{Ag}(\mathrm{I}), \mathrm{Zn}(\mathrm{II}), \mathrm{Cr}(\mathrm{III}), \mathrm{Cr}(\mathrm{VI}), \mathrm{Cd}(\mathrm{II}), \mathrm{Pt}(\mathrm{II})$ and Pd(II)have been adsorbed from aqueous solution by several modified PAN fibers $[8,9,19,20]$. The studies of adsorption were completed by investigating several parameters such as the initial concentration of metal ions, adsorbent amount, $\mathrm{pH}$, temperature as well as determine the efficiency by using thermodynamics and kinetic parameters. Table 1 presents the magnificent details of the previous result of adsorbed metal ions with the adsorption parameters, the capacity of the adsorbents, process, metal ions types, optimum $\mathrm{pH}$. Furthermore, the interactions between the chelating groups and the metal ions were studied using attenuated total reflectance Fourier transform infrared spectroscopy and X-ray photoelectron spectroscopy techniques [21-23] (Figure 3). 
Table 1: Adsorption studies of metals ions on various modified PAN.

\begin{tabular}{|c|c|c|c|c|c|}
\hline Absorbent fiber & Process & Metal ions & $\begin{array}{l}\text { Optimum } \\
\text { pH }\end{array}$ & Amount of absorbed & $\begin{array}{l}\text { Reference } \\
\text { no }\end{array}$ \\
\hline $\begin{array}{l}\text { Polyacrylonitrile fibers///PANFs } \\
\text { included } 90 \% \text { as polyacrylonitrile and } 10 \% \\
\text { as vinyl acetate }\end{array}$ & Chemical & Lead and Copper & 3.6 & $76,31 \mathrm{mg} \mathrm{g}^{-1}$ & [30] \\
\hline $\begin{array}{c}\text { Polyacrylonitrile fibers }(90 \% \text { as } \\
\text { polyacrylonitrile and } 10 \% \text { vinyl acetate }\end{array}$ & Chemical & copper ions & 5.0 & $27.95 \mathrm{mg} \mathrm{g}^{-1}$ & {$[20]$} \\
\hline Polyacrylonitrile & Chemical & $\begin{array}{l}\mathrm{Hg}(\mathrm{II}), \mathrm{Fe}(\mathrm{III}), \mathrm{Pb}(\mathrm{II}) \\
\mathrm{Ag}(\mathrm{I}) \text { and } \mathrm{Zn}(\mathrm{II})\end{array}$ & 5,2 & $\begin{array}{l}1.38 \text { and } 1.42 \mathrm{mmol} \mathrm{g}^{-1} \text { for } \\
\mathrm{Zn}(\mathrm{II}) \text { and } \mathrm{Fe}(\mathrm{III})\end{array}$ & [16] \\
\hline Polyacrylonitrile & Electrospun & $\mathrm{Fe}(\mathrm{II})$, and $\mathrm{Pb}(\mathrm{II})$ & 4.0 & $\begin{array}{l}\text { 150.6,155.5,116.5, } \\
\text { and } 60.6 \mathrm{mg} \mathrm{g}^{-1}\end{array}$ & {$[4]$} \\
\hline Polyacrylonitrile $100 \%$ & $\begin{array}{l}\text { Microwave irradi- } \\
\text { ation }\end{array}$ & $\mathrm{Cu}(\mathrm{II})$ and $\mathrm{Hg}(\mathrm{II})$ & $\begin{array}{l}5.0 \text { and } \\
2.0\end{array}$ & $1.88,1.37 \mathrm{mmol} \mathrm{g}^{-1}$ & [21] \\
\hline Polyacrylonitrile (PAN) nanofibers & Electrospun & copper ions $\mathrm{Cu}(\mathrm{II})$ & 5 and 6 & $116.522 \mathrm{mg} \mathrm{g}^{-1}$ & [13] \\
\hline Polyacrylonitrile (PAN) nanofibers & Electrospun & $\mathrm{Cu}(\mathrm{II})$ and $\mathrm{Pb}(\mathrm{II})$ & 7.0 & $\begin{array}{l}485.44 \mathrm{mg} \mathrm{g}^{-1} \\
263.15 \mathrm{mg} \mathrm{g}^{-1}\end{array}$ & [28] \\
\hline Polyacrylonitrile (PAN) 100\% & $\begin{array}{l}\text { Microwave irradi- } \\
\text { ation }\end{array}$ & $\mathrm{Cd}(\mathrm{II})$ and $\mathrm{Pb}(\mathrm{II})$ & 6 to 6.4 & $\begin{array}{l}1.47 \mathrm{mmol} \mathrm{g}^{-1} \text { and } \\
1.01 \mathrm{mmol} \mathrm{g}^{-1}\end{array}$ & [14] \\
\hline Polyacrylonitrile (PAN) & Chemical & Mercury & 4.0 & $322.6 \mathrm{mg} \mathrm{g}^{-1}$ & [29] \\
\hline Polyacrylonitrile (PAN) & Electrospun & $\mathrm{Au}(\mathrm{III})$ ions & 7.6 & $\begin{array}{l}15.86,23.50 \text { and } \\
34.60 \mathrm{mmol} \mathrm{g}^{-1}\end{array}$ & {$[32]$} \\
\hline Polyacrylonitrile (PAN) & Electrospun & $\begin{array}{l}\mathrm{Cu}(\mathrm{II}), \mathrm{Ag}(\mathrm{I}), \mathrm{Fe}(\mathrm{II}) \text {, and } \\
\mathrm{Pb}(\mathrm{II}) \text { ions }\end{array}$ & $\begin{array}{l}2.0 \text { and } \\
7.0\end{array}$ & $\begin{array}{c}150.6,155.5,116.5 \text {, and } \\
60.6 \mathrm{mg} \mathrm{g}^{-1}\end{array}$ & {$[28]$} \\
\hline Polyethylene terephthalate & Chemical & $\mathrm{Zn}^{2+}, \mathrm{Cu}^{2+}$, and $\left.\mathrm{Pb}^{2+}\right)$ & 6.0 & $\begin{array}{c}18.69,23.70, \text { and } \\
\mathrm{g}^{-1}\end{array}$ & {$[17]$} \\
\hline Amino Acid-modified PET & Chemical & Bilirubin & 7.4 & $388.69 \mathrm{mg} \mathrm{g}^{-1}$ & [33] \\
\hline Polyethylene terephthalate & Chemical & $\mathrm{Pb}(\mathrm{II})$ and $\mathrm{Cu}(\mathrm{II})$ & & $\begin{array}{c}0.2392-0.2334 \\
\text { and } 0.6648-0.7169 \mathrm{mmol} \mathrm{g}^{-1} \\
\end{array}$ & {$[24]$} \\
\hline Polyethylenimine (b- PEI) & Electrospinning & $\mathrm{Cr}(\mathrm{VI})$ & $2-6$ & $684.93 \mathrm{mg} \mathrm{g}^{-1}$ & {$[26]$} \\
\hline Polyacrylonitrile fiber & Chemical & $\begin{array}{l}\mathrm{Cu}(\mathrm{II}), \mathrm{Cd}(\mathrm{II}) \\
\mathrm{Ni}(\mathrm{II}), \text { and } \mathrm{Zn}(\mathrm{II})\end{array}$ & $\begin{array}{l}\text { below } \\
2.0\end{array}$ & $\begin{array}{l}323,278,200 \text {, and } \\
175 \mathrm{mg} \mathrm{g}^{-1}\end{array}$ & [23] \\
\hline
\end{tabular}

The hydrophilic character of the electro spun PAN fiber was increased by converting the nitrile groups of AN to amidoxime groups. For the amidoximation reaction, a recipe given in the literature was followed [24]. Hydroxylamine hydrochloride $(0.375 \mathrm{~g})$, sodium hydroxide $(0.375 \mathrm{~g})$, and $25.0 \mathrm{mg}$ of PAN nanofiber mats were added to a $50 \mathrm{~mL}$ beaker and continuously stirred for 2 days at room temperature. After the surface reaction, the nanofiber mats were washed several times with distilled water to remove the remaining salts and were dried in a vacuum oven at $60{ }^{\circ} \mathrm{C}[25]$ (Figures 4-6).

\section{Cross-linking of polyacrylonitrile fiber}

Totally, $2.0 \mathrm{~g}$ of polyacrylonitrile fibers (PAN) and $130 \mathrm{~mL}$ of $\mathrm{H}_{2} \mathrm{O}$ and $30.0 \mathrm{~g}$ of hydrazine hydrate $(80 \%)$ were added into a $250-\mathrm{mL}$ flask with refluxing for $6 \mathrm{~h}$ at $105^{\circ} \mathrm{C}$. After the reaction, the fibers were collected, washed with water until the filtration became neutral, and then washed with ethyl alcohol for three times. The resulting fibers were dried at $105^{\circ} \mathrm{C}$ (Figure 7).

\section{Preparation of polyvinyl tetrazole fiber}

To a $250-\mathrm{mL}$ three-necked flask $2.4 \mathrm{~g}$ of cross-linked PAN and $100 \mathrm{~mL}$ of DMF were added under stirring for $30 \mathrm{~min}$. The flask was then placed into an oil bath and heated to $120^{\circ} \mathrm{C}$, and $2.0 \mathrm{~g}^{\circ} \mathrm{NH}_{4} \mathrm{Cl}$,
$2.6 \mathrm{~g}$ of $\mathrm{NaN}_{3}$ were immediately added. The reaction mixture was refluxed under stirring for $16 \mathrm{~h}$. The fibers were filtered, washed with water, $0.5 \mathrm{~mol} \mathrm{~L} 1 \mathrm{HCl}$ and water in sequence, and was finally left to dry in a vacuum oven at $30^{\circ} \mathrm{C}$ [14] (Figure 8).

\section{Adsorption of Metal Ions}

For functionalized surface modification there are several techniques used including column, batch and pad batch are most common for adsorption method $[19,21,25]$. In the column, method fibers were placed a continuous flow solution through a vertical column. For chemical batch technique method, PAN fibers were placed in a metal-containing solution vessel and stirred several periods of time [9]. For pad batch technique, the simple fibers were passed through some padder with continuously flowing metal ion solution, this technique also very significant for adsorption method. After adsorption, desorption is done by applying several techniques and reused for several times (Figure 9\&10).

\section{Effect of pH}

The $\mathrm{pH}$ of the contaminated solution is the most vital factor. It affects metal-containing solution as well as adsorbents. The adsorbents chelating groups most activated for a certain $\mathrm{pH}$ and modified PAN fibers carried out different $\mathrm{pH}$ within the acidic medium to retain its functionality [26,27] (Figure 11). 


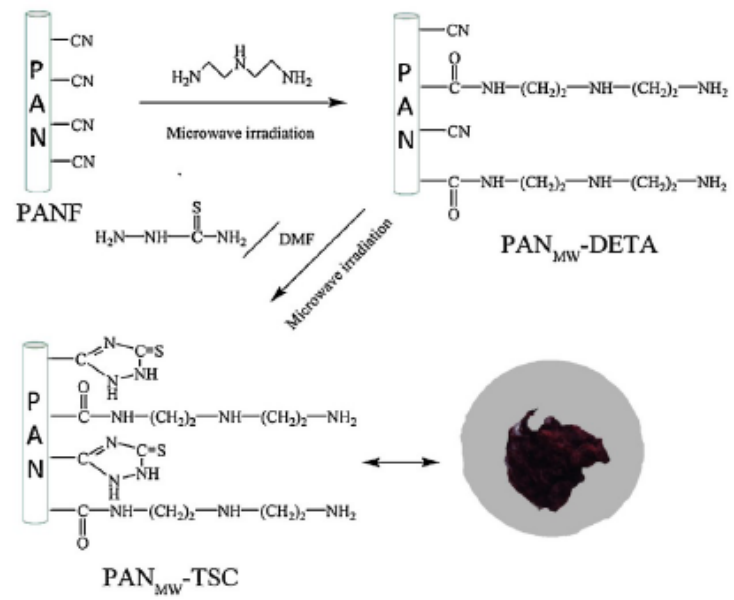

Figure 1: Synthesis routine of PAN-TSC based on polyacrylonitrile fiber [15]

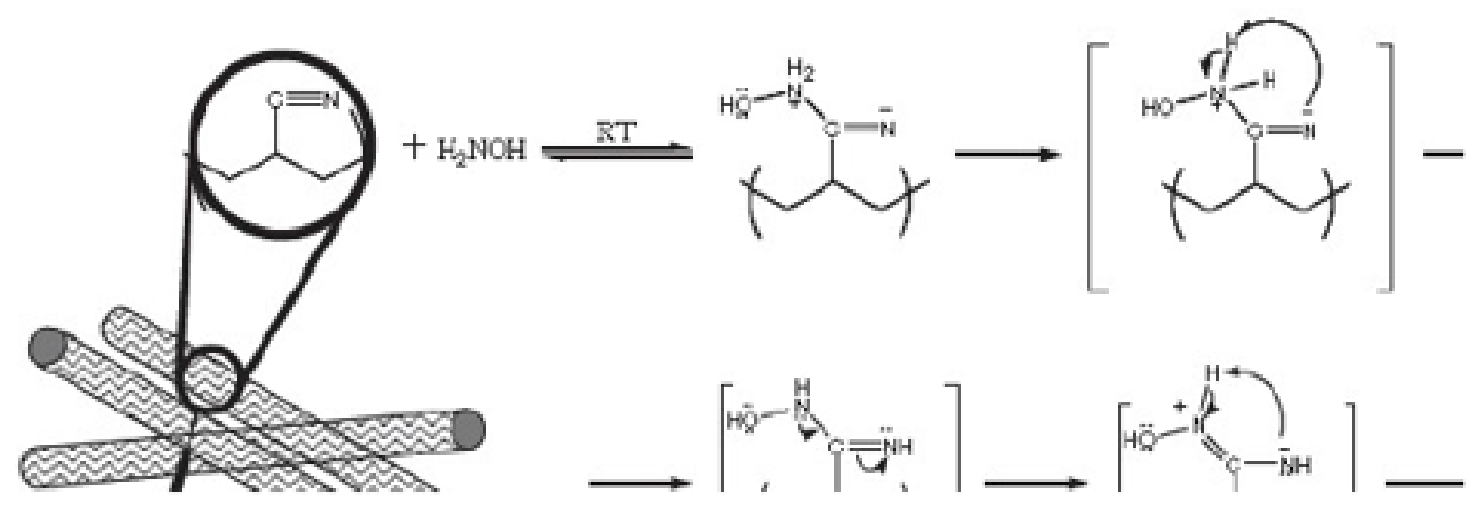

Figure 2: Synthesis routine of PAN-TSC based on polyacrylonitrile fiber [15]

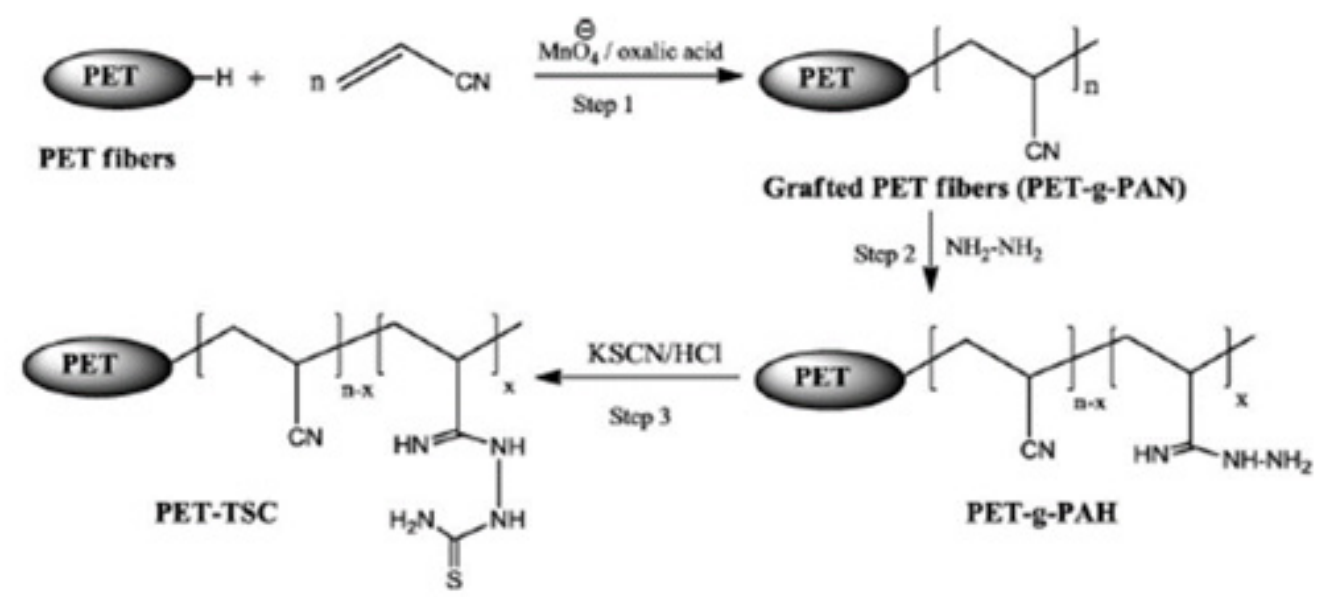

Figure 3: Synthesis of PET-TSC chelating fibers [9] 


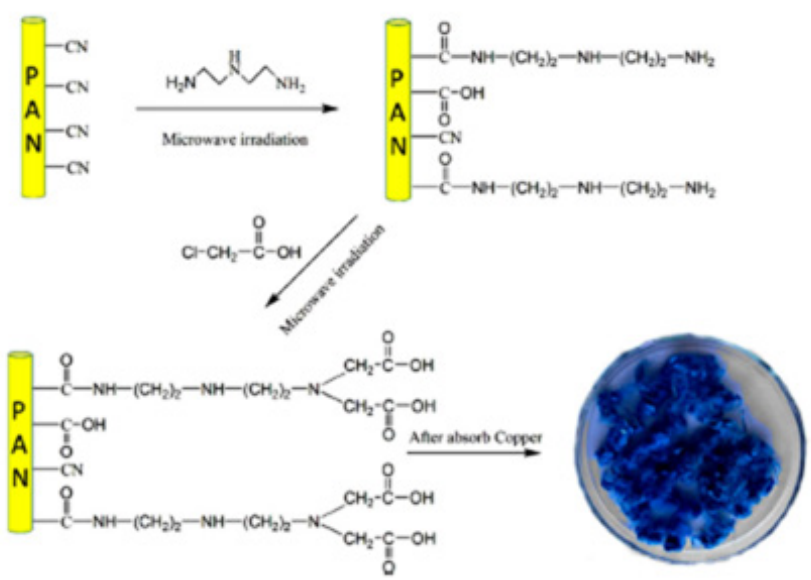

Figure 4: The synthetic scheme of PANMW-IDA [21].

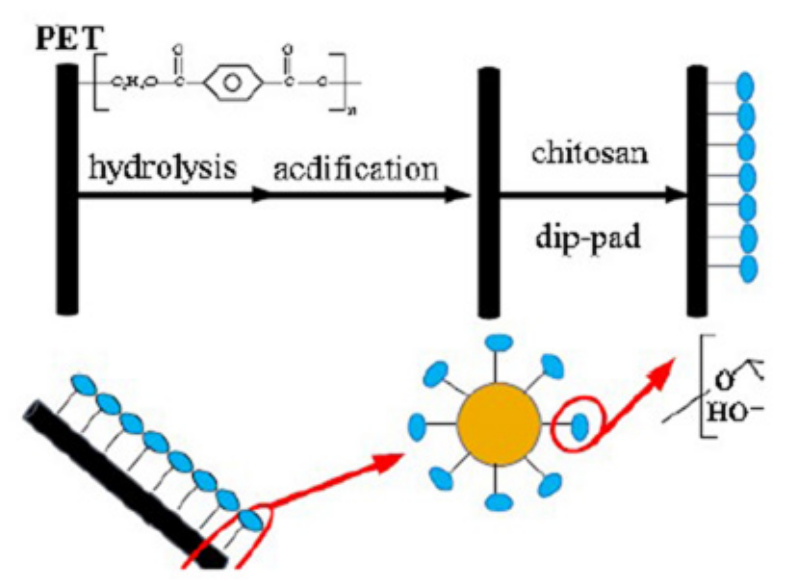

Figure 5: Schematic of CCP preparation process Copyright form [17].
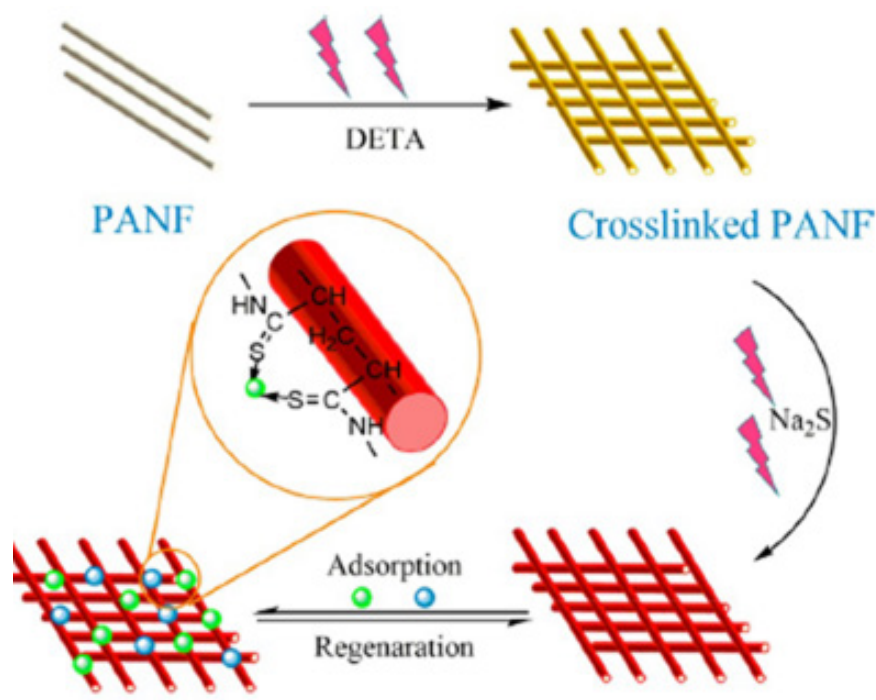

PAN $_{\mathrm{MW}}$-Thio

Microwave irradiation $\bigcirc \mathrm{Hg} \quad \circ \quad \mathrm{Cd}$

Figure 6: Schematic of PANMW-Thio fiber preparation by the MW assisted method [18]. 


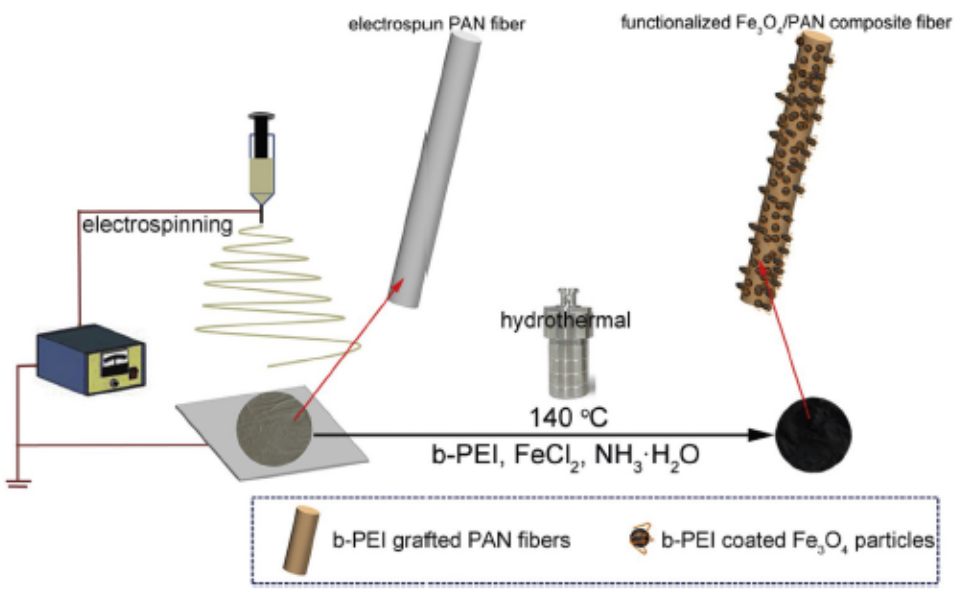

Figure 7: Schematic diagram of the synthesis of functionalized Fe304/PAN composite electro spun fibers [26].

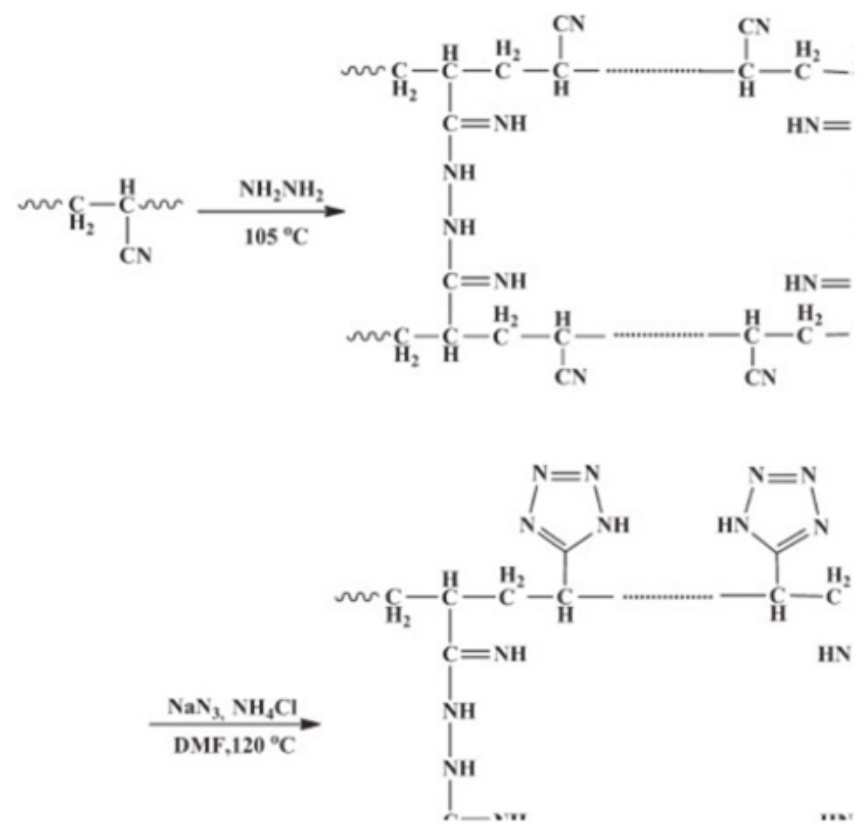

Figure 8: Synthesis route of PVT [23].

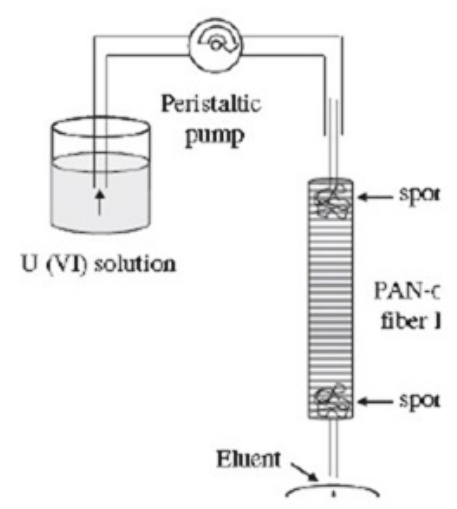

Figure 9: Schematic representation of experimental setup of column experiment [2]. 


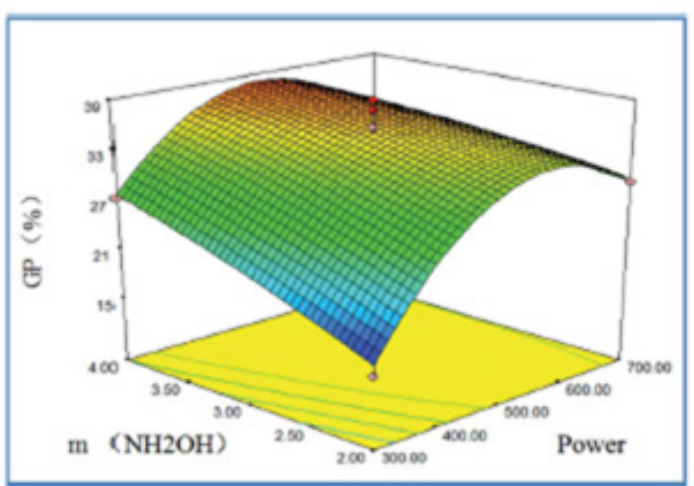

Figure 10: Response surface plot for GP\% of PANMW-AO fibers showing the interaction between power of radiation $(\mathrm{W})$ and mass of $\mathrm{NH} 2 \mathrm{OH} \$ \mathrm{HCl}(\mathrm{g})$ (time 1 _ 5 , bath ratio at 50 : 1) [19].
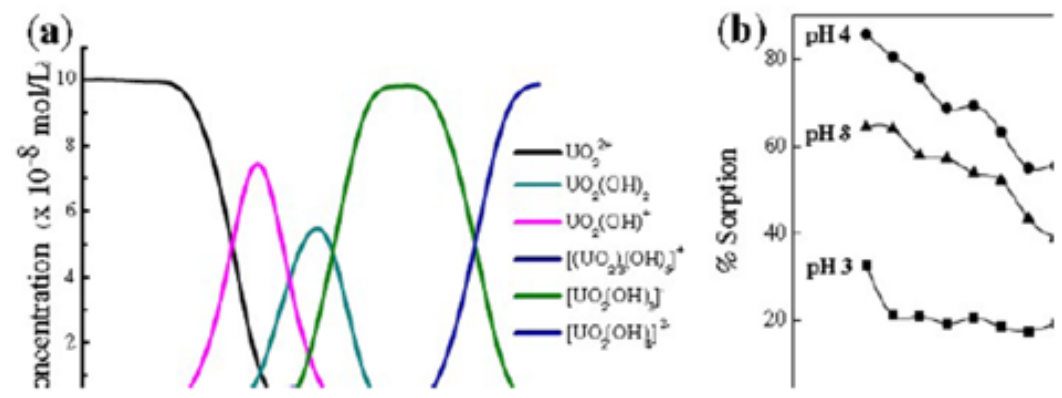

Figure 11: (a) Speciation diagram of $\mathrm{U}(\mathrm{VI})$ and (b) microcolumn study of $\mathrm{U}(\mathrm{VI})$ at different $\mathrm{pH}$ values.

Reaction conditions: initial U(VI) concentration of $100 \mathrm{mg} \mathrm{L}-1,0.15 \mathrm{~mL} \mathrm{~min}-1$ flow rate, $25.0 \mathrm{mg}$ sorbent [2]

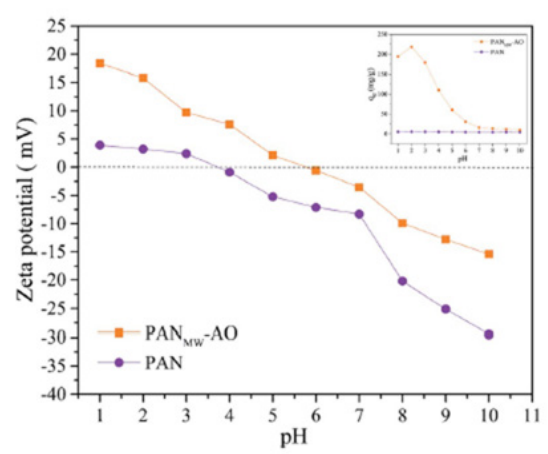

Figure 12: Effect of $\mathrm{pH}$ on the adsorption of $\mathrm{Cr}(\mathrm{VI})$ onto the PANMW-AO fibers [19].

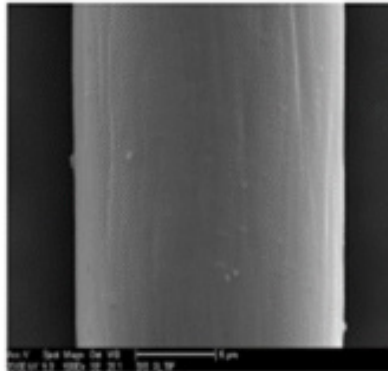

(a)

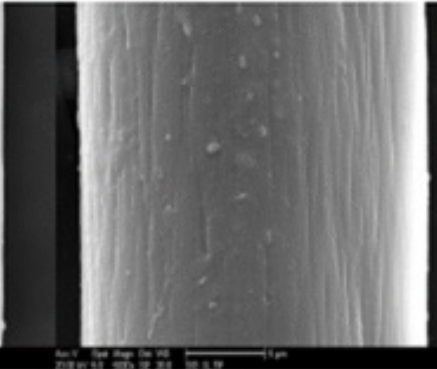

(b)

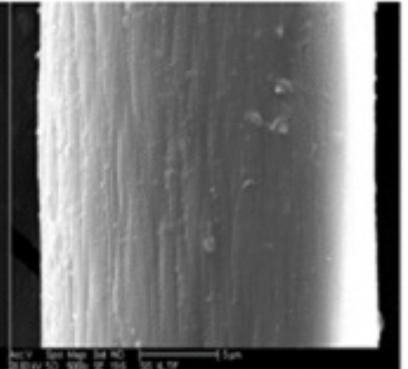

(c)

Figure 13: SEM characterization of (a) PANF, (b) PANMW-DETA and (c) PANMW-IDA [21]. 


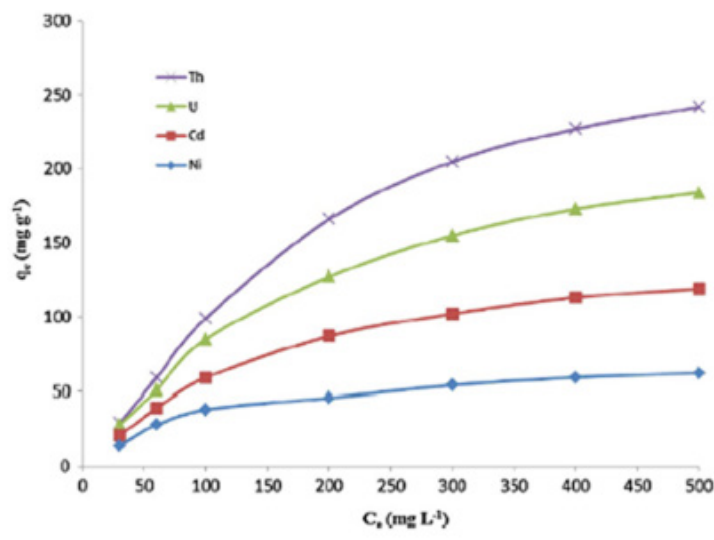

Figure 14: The effect of initial concentrations on the adsorption of Th(IV), $\mathrm{U}(\mathrm{VI}), \mathrm{Ni}(\mathrm{II})$ and $\mathrm{Cd}(\mathrm{II})$, at optimum $\mathrm{pH}$ for each metal, adsorbent dose $1 \mathrm{~g} \mathrm{~L}^{-1}$ and $\mathrm{T}=45 \mathrm{C}$ [25].
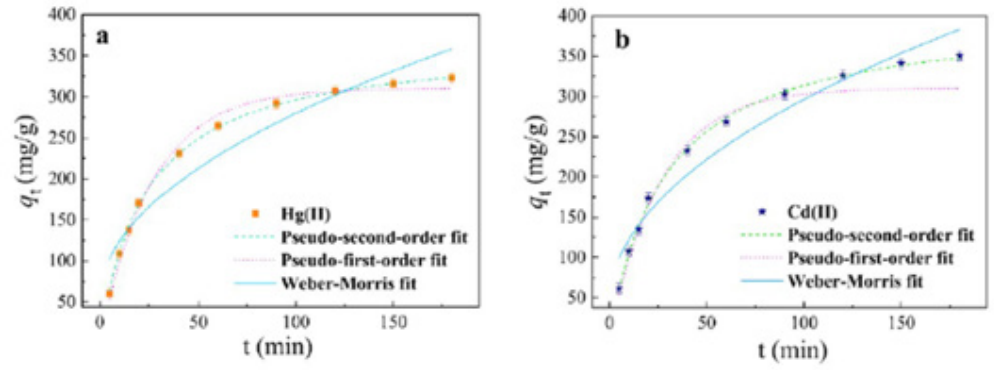

Figure 15: Adsorption kinetics curves of $\mathrm{Hg} 2+$ and $\mathrm{Cd} 2+$ on PANMW-Thio fibers [18].

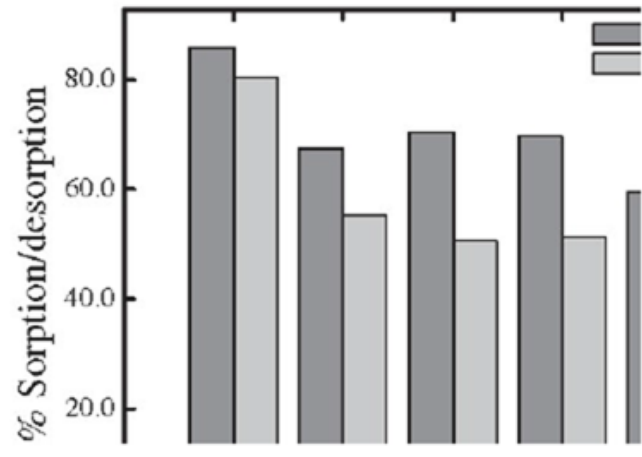

Figure 16: Consecutive sorption/desorption cycles of amidoximated PAN fiber for $100 \mathrm{mg} \mathrm{L-1} \mathrm{U(VI)} \mathrm{solution}$ using $0.5 \mathrm{M} \mathrm{NaHCO} 3$ as the desorbing agent [2].

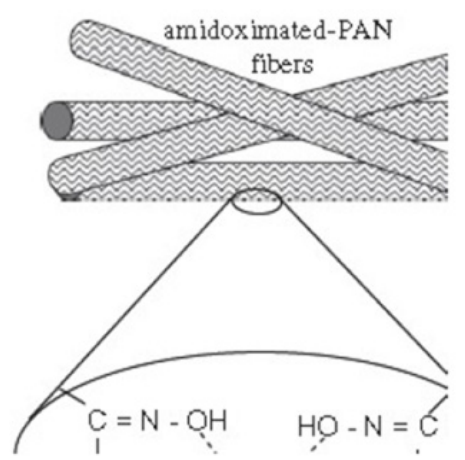

Figure 17: Speculative binding mechanism [2]. 


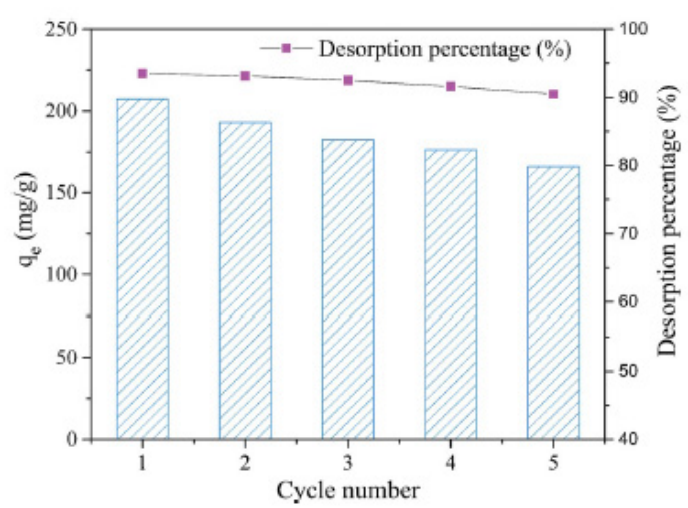

Figure 18: Adsorption capacity of the PANMW-AO fibers after five repeated regenerations [19].

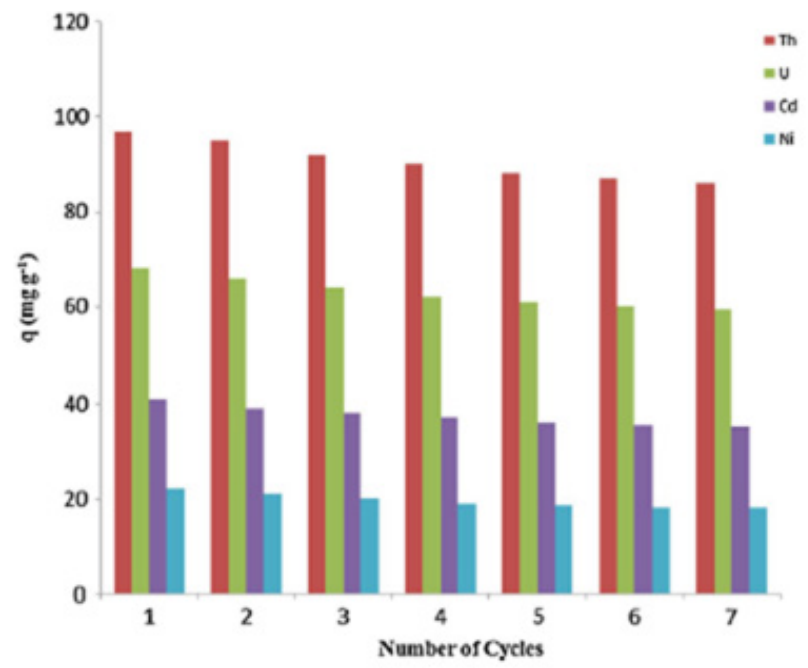

Figure 19: Seven cycles of $\mathrm{Th}^{4+}, \mathrm{U}^{6+}, \mathrm{Cd}^{2+}$ and $\mathrm{Ni}^{2+}$ adsorption-desorption with the initial metal ion concentration of $100 \mathrm{mg} \mathrm{L}-1$, optimum $\mathrm{pH}$ for each metal and $25 \mathrm{C}$ [25].

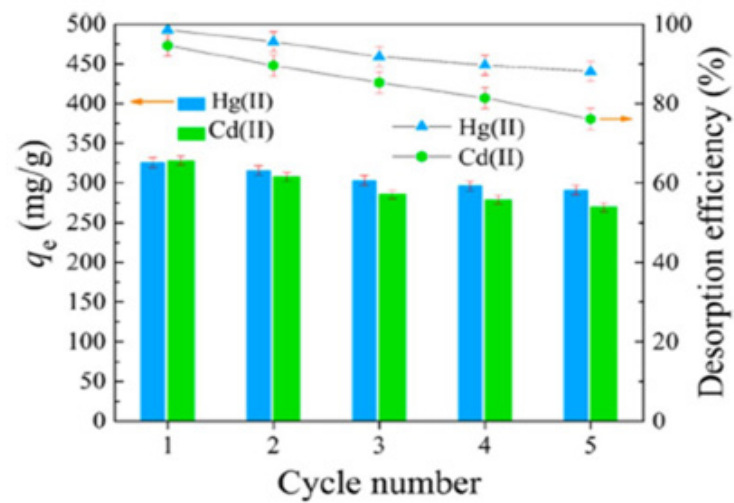

Figure 20: Adsorption capacities of $\mathrm{Hg} 2+$ and $\mathrm{Cd} 2+$ on PANMW-Thio fibers after five times regeneration [18].

The $\mathrm{pH}$ of the adsorption media has a great effect on the ionic state of the functional groups on the surface of the adsorbent. The effect of $\mathrm{pH}$ was investigated for the Th(IV), U(VI), Ni(II) and Cd(II) adsorption in the $\mathrm{pH}$ 1-7 range including the initial concentration $100 \mathrm{mg} \mathrm{L}^{-1}$, adsorbent $1 \mathrm{gL}^{-1}$ and temperature $25^{\circ} \mathrm{C}$. The result found that the maximum adsorption was observed in the $\mathrm{pH} 4,5$, 6 and 6.5 for the Th(IV), U(VI), Ni(II) and Cd(II) on the adsorbent.
The influence of $\mathrm{pH}$ on the metal ions adsorption could be clarified by $\mathrm{pH}$ value (Figure 12).

$\mathrm{pH}<\mathrm{pHpzc}$, the adsorbent surface acted positive, as a result of the positive charge on adsorption surface and

metal ions repulsion each other due to electrostatic behavior; hampered the adsorption capacity. And, when $\mathrm{pH}>\mathrm{pHpzc}$, the 
adsorbent surface acted negatively; it resulted in a negative charge on the surface created further attractions with the metal ions. By this way build up the complex formation of metal ions with the adsorbent surface functional group and the adsorption capacity highly increased [25] (Figure 13).

The pH plays an important role in metal adsorption which is related to both the metal species and the availability of binding site which depends on the functional group of the sorbent [31]. The metal species, $\mathrm{M}(\mathrm{II}) ; \mathrm{Cu}(\mathrm{II}), \mathrm{Pb}(\mathrm{II})$ and $\mathrm{Fe}(\mathrm{II})$, are present in forms of $\mathrm{M}^{2+}, \mathrm{M}(\mathrm{OH})^{+}, \mathrm{M}(\mathrm{OH})_{2}(\mathrm{~S})$, etc. in water [28]. The solubility of the $\mathrm{M}(\mathrm{OH})_{2}(\mathrm{~S})$ is very high at $\mathrm{pH} 5.0$, so a large amount of the $\mathrm{M}^{2+}$ presents as main species. When $\mathrm{pH}$ is increasing the solubility of $\mathrm{M}(\mathrm{OH})_{2}(\mathrm{~S})$ decrease resulting in the main species in the solution is $\mathrm{M}(\mathrm{OH})_{2}(\mathrm{~S})$ instead. It can tell that the $\mathrm{M}^{2+}$ must be much more reduce at higher $\mathrm{pH}$, but the major process for removing the $\mathrm{M}^{2+}$ is the precipitation, not adsorption. To avoid the precipitation of metal ions, no adsorption experiments were done at a $\mathrm{pH}$ greater than 7 (Table 1).

\section{Initial concentration of ions}

The primary concentration of the metal ions solution is measured by the parts per million $\left(\mathrm{mgL}^{-1}\right)$. The metalions concentration is prepared according to obey the World Health Organization (WHO) standards for better performance of the adsorbent. The modified PAN fibers adsorption study showed that the adsorption mainly depends on the primary concentration of the metal ions solution. If the concentration is higher the adsorption rate showed higher. Once a time, there was no sufficient place to adsorb onto the adsorption surface and then the rate of adsorption decrease $[9,27]$ (Figure 14).

\section{Effect of contact time}

The amount of adsorption depends on the contact time of the metal ions solution. The adsorption rate is higher for the first moment and it gradually decreases with time. The adsorption rate is three times faster in the initial moment but it sharply declines with time [21]. The adsorption of the metal ions on the PAN nanofiber increased rapidly with an initial increase in the contact time to finally reach the maximal. The adsorption of metal ions onto the surface of the PAN nanofiber occurred in two steps. Initially, the adsorption was very fast because a large number of vacant surface sites are available for adsorption. In the second step, adsorption rates decreased and finally reached equilibria. This result from the reduction of available sites which are difficult to be occupied due to repulsive forces between the solute molecules adsorbed on the solid surface and the bulk phase $[27,28,33]$.

Figure 15 showed that the adsorption amount increased rapidly during the first $60 \mathrm{~min}$, and over $50 \%$ of the equilibrium adsorption was obtained. Afterward, the adsorption rate became gentle, and the equilibrium was accessed within $4 \mathrm{~h}$. Initially, the fast adsorption rate may be attributed to the high concentration of metal ions, along with the large amount of active adsorption sites within PANMW-Thio fibers. As the adsorption amount of $\mathrm{Hg}^{2+}$ or $\mathrm{Cd}^{2+}$ onto the adsorbent increased, the repulsive forces between the adsorbed species are boosted, and adsorption resistance for free metal ions is exacerbated accordingly.

\section{Desorption}

There are several methods used for the desorption technique as well as regeneration of the heavy metal adsorbent. Normally acid and basis method was popular but be careful when handling, didn't allow to damage the sample. Here investigated regeneration was done with $0.5 \mathrm{M} \mathrm{HNO}_{3}$ which is perfectly suitable for five times reused, performance little decreased resulted $85 \%$ capable and was the potential application for the effluent water treatment [23] (Figure 16-18).

\section{Conclusions}

This work demonstrated that amidoximated PAN fibers produced by electrospinning are an effective sorbent for the removal of heavy metal ions from aqueous media. A wet chemical process was applied for surface modification of PAN fibers. The nitrile groups on the PAN fibers were converted to amidoxime groups using hydroxylamine hydrochloride in a neutralized medium. The surface-functionalized PAN fiber network provided higher metal-binding ability. The amidoximated PAN liter materials demonstrated high mechanical resistance, sorption ability, and efficient reusability, which are desired for filtration applications as well as adsorption of metal ions including Fe(III), $\mathrm{Cu}(\mathrm{II}), \mathrm{Cd}(\mathrm{II})$ and etc. from aqueous solutions. There were various modifications of PAN fibers for the adsorption of different heavy metal ions from the solution. The PAN adsorbents show strong ability to adsorb heavy metal ions from aqueous solution and the adsorption fitted Langmuir monolayer adsorption model for $\mathrm{Cu}(\mathrm{II}), \mathrm{Cd}(\mathrm{II}), \mathrm{Ni}(\mathrm{II})$, and $\mathrm{Zn}(\mathrm{II})$. The adsorbent also presents good reuse ability and higher stability. Impact parameters such as $\mathrm{pH}$, contact time, initial concentration of ions etc. were systemically discussed. In practical application, the adsorbent could efficiently remove $\mathrm{Cu}(\mathrm{II}), \mathrm{Cd}(\mathrm{II})$, $\mathrm{Ni}(\mathrm{II})$, and $\mathrm{Zn}(\mathrm{II})$ ions in wastewater. Therefore, the prepared functionalized PAN fibers adsorbents were expected to find wide application in the enrichment and removal of virous heavy metal ions from wastewater, and the established method might become a promising way to recycle waste polyacrylonitrile (Figures 19\&20).

\section{Acknowledgements}

We gratefully thank Prof. Shixing Wang (Kunming University of Science and Technology) for valued discussion. Financial support from Research Fund for Advanced Talents (163083) and Hubei Province Technical Innovation Special Project (2019AAA005) were gratefully acknowledged.

\section{Conflict of Interest}

Authors declare no conflict of interest. 


\section{References}

1. Fu F, Wang Q (2011) Removal of heavy metal ions from wastewaters: a review. J Environ Manage 92(3): 407-418.

2. Horzum N, Shahwan T, Parlak O, Demir MM (2012) Synthesis of amidoximated polyacrylonitrile fibers and its application for sorption of aqueous uranyl ions under continuous flow. Chem Eng J 213: 41-49.

3. Chen JP, Hong L, Wu S, Wang L (2002) Elucidation of interactions between metal Ions and Ca alginate-based ion-exchange resin by spectroscopic analysis and modeling simulation. Langmuir 18(24): 9413-9421.

4. Bode-Aluko CA, Pereao O, Fatoba O, Petrik L (2017) Surface-modified polyacrylonitrile nanofibres as supports. Polym Bull 74: 2431-2442.

5. Bodealuko C, Pereao O, Ndayambaje G, Petrik LF (2017) Adsorption of heavy metals on modified polyacrylonitrile nanofibres: a review. Water Air Soil Poll 228(1): 35.

6. Jin L, Bai R (2002) Mechanisms of lead adsorption on chitosan/PVA hydrogel beads. Langmuir 18(25): 9765- 9770.

7. Coskun R, Yigitoglu M, Sacak M (2000) Adsorption behavior of copper(II) ion from aqueous solution on methacrylic acid-grafted poly(ethylene terephthalate) fibers. J Appl Polym Sci 75(6): 766-772.

8. Lacour S, Bollinger J, Serpaud B, Chantron P, Arcos R (2001) Removal of heavy metals in industrial wastewaters by ion-exchanger grafted textiles. Anal Chim Acta 428(1): 121-132.

9. Monier M, Abdellatif DA (2013) Modification and characterization of PET fibers for fast removal of $\mathrm{Hg}(\mathrm{II}), \mathrm{Cu}(\mathrm{II})$ and $\mathrm{Co}(\mathrm{II})$ metal ions from aqueous solutions. J Hazard Mater 250-251: 122-130.

10. Sadeghi S, Azhdari H, Arabi H, Moghaddam A (2012) Surface modified magnetic $\mathrm{Fe}_{3} \mathrm{O}_{4}$ nanoparticles as a selective sorbent for solid phase extraction of uranyl ions from water samples. J Hazard Mater 215-216: 208-216.

11. Comarmond J, Payne T, Harrison J, Thiruvoth S, Wong H, et al. (2011) Uranium sorption on various forms of titanium dioxide- influence of surface area, surface charge, and impurities. Environ Sci Technol 45(13): 5536-5542.

12. Hong G, Li X, Shen L, Wang M, Wang C, et al. (2015) High recovery of lead ions from aminated polyacrylonitrile nanofibrous affinity membranes with micro/nano structure. J Hazard Mater 295: 161-169.

13. Neghlani P, Rafizadeh M, Taroni F (2011) Preparation of aminatedpolyacrilonitrile nanofiber membranes for the adsorption of metal ions: comparison with microfibers. J Hazard Mater 186: 182-189.

14. Deng S, Wang P, Zhang G, Dou Y (2016) Polyacrylonitrile-based fiber modified with thiosemicarbazide by microwave irradiation and its adsorption behavior for Cd(II) and Pb(II). J Hazard Mater 307: 64-72.

15. Shin DH, Ko YG, Choi US, Kim WN (2004) Design of high efficiency chelate fibers with an amine group to remove heavy metal ions and pH-related FT-IR analysis. Ind Eng Chem Res 43(9): 2060-2066.

16. Kiani GR, Sheikhloie H, Arsalani N (2011) Heavy metal ion removal from aqueous solutions by functionalized polyacrylonitrile. Desalination 269(1-3): 266-270.

17. Niu Y, Ying D, Li K, Wang Y, Jia J (2017) Adsorption of heavy-metal ions from aqueous solution onto chitosan-modified polyethylene terephthalate (PET). Res Chem Intermediates 43: 4213-4225.

18. Deng S, Zhang G, Liang S, Wang P (2017) Microwave assisted preparation of thio-functionalized polyacrylonitrile fiber for the selective and enhanced adsorption of mercury and cadmium from water. ACS Sustain Chem Eng 5(7): 6054-6063.
19. Deng S, Zhang G, Li Y, Dou Y, Wang P (2016) Facile preparation of amidoxime-functionalized fiber by microwave-assisted method for the enhanced adsorption of chromium(VI) from aqueous solution. RSC Adv 6: 64665-64675.

20. Jiang Z, Liu Y, Zeng G, Xu W, Zheng B, et al. (2015) Adsorption of hexavalent chromium by polyacrylonitrile (PAN)-based activated carbon fibers form aqueous solution. RSC Adv 5: 25389.

21. Deng S, Zhang G, Wang X, Zheng T, Wang P (2015) Preparation and performance of polyacrylonitrile fiber functionalized with iminodiacetic acid under microwave irradiation for adsorption of $\mathrm{Cu}(\mathrm{II})$ and $\mathrm{Hg}$ (II). Chem Eng J 276: 349-357.

22. Soltanzadeh M, Kiani G, Khataee A (2014) Adsorptive capacity of polyacrylonitrile modified with triethylenetetramine for removal of copper and cadmium ions from aqueous solutions. Environ Prog Sustain. Energy 33(4): 1139-1147.

23. Yan S, Zhao M, Lei G, Wei Y (2012) Novel tetrazole-functionalized absorbent from polyacrylonitrile fiber for heavy-metal ion adsorption. J Appl Polym Sci 125(1): 382-389.

24. Zhang Y, Ren Y, Liu X, Huo T, Qin Y (2018) Preparation of durable flame retardant PAN fabrics based on amidoximation and phosphorylation. Appl Surf Sci 428: 395-403.

25. Dastbaz A, Keshtkar AR (2014) Adsorption of $\mathrm{Th}^{4+}, \mathrm{U}^{6+}, \mathrm{Cd}^{2+}$, and $\mathrm{Ni}^{2+}$ from aqueous solution by a novel modified polyacrylonitrile composite nanofiber adsorbent prepared by electrospinning. Appl Surf Sci 293: 336-344.

26. Zhao R, Li X, Li Y, Li Y, Sun B, et al. (2017) Functionalized magnetic iron oxide/polyacrylonitrile composite electrospun fibers as effective chromium (VI) adsorbents for water purification. J Colloid Interf Sci 505: 1018-1030.

27. Wang J, Xu L, Cheng C, Meng Y, Li A (2012) Preparation of new chelating fiber with waste PET as adsorbent for fast removal of $\mathrm{Cu}^{2+}$ and $\mathrm{Ni}^{2+}$ from water: Kinetic and equilibrium adsorption studies. Chem Eng J 193-194: 31-38.

28. Haider S, Park S (2009) Preparation of the electrospun chitosan nanofibers and their applications to the adsorption of $\mathrm{Cu}(\mathrm{II})$ and $\mathrm{Pb}(\mathrm{II})$ ions from an aqueous solution. J Membrane Sci 328(1-2): 90-96.

29. Li N, Bai R, Liu C (2005) Enhanced and selective adsorption of mercury ions on chitosan beads grafted with polyacrylamide via surface-initiated atom transfer radical polymerization, Langmuir 21(25): 11780-11787.

30. Deng S, Bai R, Chen JP (2003) Aminated polyacrylonitrile fibers for lead and copper removal. Langmuir 19(12): 5058-5064.

31. Kampalanonwat P, Supaphol P (2010) Preparation and adsorption behavior of aminated electrospun polyacrylonitrile nanofiber mats for heavy metal ion removal. ACS Appl Mater Interfaces 2(12): 3619- 3627.

32. Li X, Zhang C, Zhao R, Lu X, Xu X, et al. (2013) Efficient adsorption of gold ions from aqueous systems with thioamide-group chelating nanofiber membranes. Chem Eng J 229: 420-428.

33. Xu X, Zhang F, Wang W, Li N, Zhuang X, et al. (2017) Development of amino acid-modified PET/PA6 segmented pie bicomponent spunbonded microfiber nonwoven for bilirubin affinity adsorption. Fiber Polym 18: 633-640. 
